\title{
Lyme disease risk in southern California: abiotic and environmental drivers of Ixodes pacificus (Acari: Ixodidae) density and infection prevalence with Borrelia burgdorferi
}

Andrew J. MacDonald ${ }^{1,2^{*}}$, David W. Hyon ${ }^{1}$, John B. Brewington III', Kerry E. O'Connor ${ }^{3}$, Andrea Swei ${ }^{3}$ and Cheryl J. Briggs ${ }^{1}$

\begin{abstract}
Background: Tick-borne diseases, particularly Lyme disease, are emerging across the northern hemisphere. In order to manage emerging diseases and predict where emergence will likely occur, it is necessary to understand the factors influencing the distribution, abundance and infection prevalence of vector species. In North America, Lyme disease is the most common vector-borne disease and is transmitted by blacklegged ticks. This study aimed to explore the abiotic and environmental drivers of density and infection prevalence of western blacklegged ticks (Ixodes pacificus) in southern California, an understudied and densely populated region of North America.

Results: Over the course of this two-year study, densities of I. pacificus adults were consistently positively associated with host availability for juvenile ticks and dense oak woodland habitat. Densities of nymphal and larval I. pacificus, on the other hand were primarily predicted by host availability for juvenile ticks in the first year of the study, and by habitat characteristics such as dense leaf litter in the second year. Infection with the causative agent of Lyme disease, Borrelia burgdorferi (sensu stricto), and related spirochetes was not predicted by the abiotic conditions promoting I. pacificus populations, but rather by diversity of the tick community, and in particular by the presence of two Ixodes tick species that do not generally feed on humans (Ixodes spinipalpis and Ixodes peromysci). Borrelia spp. infection was not detected in the I. pacificus populations sampled, but was detected in other vector species that may maintain enzootic transmission of the pathogen on the landscape.

(Continued on next page)
\end{abstract}

\footnotetext{
* Correspondence: andy.j.macdon@gmail.com

'Department of Ecology, Evolution and Marine Biology, University of

California, Santa Barbara, CA 93106-9620, USA

2Department of Biology, Stanford University, 371 Serra Mall, Stanford, CA

94305, USA

Full list of author information is available at the end of the article
} 
(Continued from previous page)

Conclusions: This study identified dense oak woodlands as high-risk habitats for I. pacificus tick encounter in southern California. The shift in relative importance of host availability to habitat characteristics in predicting juvenile tick abundance occurred as California's historic drought intensified, suggesting that habitat providing suitable microclimates for tick survivorship became centrally important to patterns of abundance in the face of deleterious abiotic conditions. These results underscore the need for further investigation of the effects of climate change on tick-borne disease in California. Finally, despite low risk of human Lyme disease infection posed by I. pacificus in southern California, evidence of infection was found in other tick species, suggesting that enzootic transmission of tick-borne borreliae may be occurring in southern California, and involve parallel enzootic cycles with other tick and host species but not necessarily humans.

Keywords: Partial least squares regression, Ixodes spinipalpis, Ixodes peromysci, Borrelia bissettiae, Enzootic transmission, Vector diversity, Drought

\section{Background}

In recent decades numerous vector-borne zoonotic diseases (VBZDs) have emerged, including West Nile virus, chikungunya, Zika virus, Powassan virus and tick-borne relapsing fever. Further, endemic regions where VBZDs have historically circulated are experiencing increases in human incidence and transmission intensity in vector populations and wildlife hosts $[1,2]$. Transmission of VBZDs to humans requires the interaction of human populations with natural pathogen transmission cycles between competent vectors and reservoir hosts at the human-animal interface [3]. Understanding the factors that influence the distribution and abundance of vector species [2], as well as infection prevalence in vector populations is thus critical to an understanding of human risk of infection with VBZDs. For VBZDs, because humans are often dead-end hosts and do not maintain pathogen transmission cycles, infection prevalence in vector populations and thus risk of transmission to humans are driven primarily by wildlife reservoirs and enzootic pathogen transmission cycles [2]. Management and control of such zoonoses is quite difficult because vaccination or treatment of human populations has no effect on underlying enzootic transmission, and infection is determined largely by contact with vectors $[2,4]$. Strategies for disease control involving environmental management or land use planning $[5,6]$ may be increasingly important due to development of resistance to insecticides in vector populations and the challenges associated with managing enzootic transmission cycles [7, 8]. Such management strategies require an understanding of the abiotic and environmental conditions that promote both vector populations and elevated infection prevalence with zoonotic pathogens on the landscape.

In this study, the influence of environmental and abiotic factors on densities of the primary vector of Lyme disease in the western United States (US), Ixodes pacificus, as well as infection prevalence of vector ticks with the causative agent in North America, Borrelia burgdorferi (sensu stricto) (s.s.), were investigated in southern California. Tick-borne diseases, such as Lyme disease, are particularly challenging to manage because tick populations are difficult to control [8] and environmental or landscape risk factors conducive to high tick abundance are often not well understood [9]. Lyme disease, which is caused by the spirochete bacterium B. burgdorferi (s.s.) and vectored by ticks in the genus Ixodes, is one of the most common tickborne diseases globally. In North America, there are distinct Lyme disease foci in the eastern, upper midwestern and far western regions of the US and Canada. In the far western US, human incidence of Lyme disease is highest in northwestern California and investigations of the ecology of this disease system have largely focused on that region. In northern California, dense oak woodland habitats tend to harbor the highest densities of I. pacificus ticks, particularly for the larval and nymphal stages; they also experience higher nymphal infection prevalence with B. burgdorferi (s.s.), both key elements of entomological risk of human infection [10-12]. Within oak woodland habitats, temperature - particularly maximum summer temperatures - relative humidity, elevation, aspect and presence of dense leaf litter have been found to be important predictors of tick density and/or infection prevalence [13-15]. These associations suggest that a combination of direct, e.g. accelerated molting and mortality due to high summer temperatures [13], and indirect, e.g. influences on densities of key tick hosts and pathogen reservoirs, effects of abiotic and habitat conditions determine tick density and infection prevalence in northwestern California [15].

However, there is evidence that suggests these abiotic and environmental factors may not be predictive of entomological risk in central and southern California where nymphal I. pacificus questing behavior appears to differ markedly from that observed in Lyme-endemic northwestern California [16, 17]. Densities of questing nymphal I. pacificus are extremely low in oak woodland sites in southern California $[16,17]$ relative to infestation 
of western fence lizards (Sceloporus occidentalis), a key host for juvenile I. pacificus and an effective sentinel animal for detecting juvenile tick activity in this region [17]. This suggests both that: (i) risk of human exposure to nymphal $I$. pacificus in southern California is relatively low and likely to be highly localized to areas with habitat types, abiotic conditions and host assemblages that promote nymphal questing activity; and (ii) due to comparatively high densities of questing adult I. pacificus relative to nymphs, possibly due to differences in questing behavior in the nymphal stage [16], exposure to adult female ticks may present greater risk in central and southern California than exposure to nymphal ticks $[16,17]$.

Thus, in this study we were interested in determining whether dense oak woodland habitats are associated with elevated densities of nymphal $I$. pacificus and whether different habitat and abiotic conditions might be better predictors of exposure to adult I. pacificus, and therefore aggregate entomological risk, in southern California. Given the low densities of nymphal I. pacificus observed in previous studies [16, 17], we expected to find elevated densities of nymphal ticks to be narrowly associated with dense oak woodland habitat, higher in elevation, with dense leaf litter in the understory, which together promote microclimatic conditions found to be important to nymphal tick abundance in northern California [10, 11, 14, 15]. Similarly, we expected elevated adult tick density to be associated with dense oak woodland, or forest edge habitats where deer, important reproductive hosts for adult ticks, tend to forage. Additionally, we addressed whether these same abiotic and habitat conditions predict vector tick infection with B. burgdorferi (s.s.) on the landscape or whether this pathogen may be associated with different habitats and environmental conditions in southern California. Again, we expected a similar pattern, with elevated infection prevalence associated with dense oak woodland habitats as in northern California [10, 14, 15]. To elucidate the habitat and abiotic factors associated with elevated entomological risk (e.g. elevated densities of infected ticks) for Lyme disease in this understudied region, tick surveys were conducted in Santa Barbara County, California. Over 2 years, surveys were conducted in plots that represent a range of habitats with varying environmental and abiotic conditions.

\section{Methods}

\section{Field sites, tick sampling and environmental data collection}

Questing ticks were collected in 24, $50 \times 50 \mathrm{~m}$ plots across three sites in Santa Barbara County, California. Climatic conditions in this region are Mediterranean with cool, wet winters and warm, dry summers with microclimatic variation driven largely by topography and habitat characteristics. The three sites selected were: (i) Sedgwick Reserve $\left(34^{\circ} 42^{\prime} 04.38^{\prime \prime N}, 120^{\circ} 02^{\prime} 50.81^{\prime \prime W}\right)$, a 2388 ha reserve that is part of the University of California Natural Reserve System (UCNRS) and located in the Santa Ynez Valley ( $\times 10$ plots); (ii) Paradise Reserve $\left(34^{\circ} 32^{\prime} 22.07^{\prime \prime} \mathrm{N}, 119^{\circ} 47^{\prime} 51.89^{\prime \prime W}\right)$, a $\sim 67$ ha privately owned natural area located on the north side of the Santa Ynez Mountains in the Los Padres National Forest ( $\times 4$ plots); and (iii) Coal Oil Point Reserve (34 $24^{\prime} 52.96^{\prime \prime} \mathrm{N}$, $119^{\circ} 52^{\prime} 48.59$ "W), a 69 ha coastal reserve that is part of the UCNRS and located west of the University of California, Santa Barbara campus ( $\times 10$ plots) (Fig. 1). These three sites were chosen because they represent a range of habitat types, abiotic conditions and degree of maritime influence common in this region. Coal Oil Point experiences a significant marine influence, which moderates temperature extremes and provides fog water subsidies, with habitat dominated by coastal scrub, grassland and patches of coast live oak (Quercus agrifolia). Sedgwick experiences less maritime influence, with generally warmer summers and colder winters, with habitats dominated by oak woodland on north facing slopes, oak savannah in valleys, as well as grassland and chaparral/scrub. Paradise Reserve is dominated by oak woodland with patches of open grassland and chaparral/scrub habitat interspersed, and experiences lower temperature extremes than Sedgwick, but less maritime influence than Coal Oil Point. Plots were chosen within each of these three sites using a stratified-random design to ensure that different habitat types (oak woodland, oak savannah and chaparral/grassland) with a range of abiotic and environmental conditions were sampled equally across all three sites. Habitat types were classified based on satellite imagery from Google Earth and subsequently groundtruthed (see below). Plots were chosen randomly, and located at least $200 \mathrm{~m}$ apart, within each broad habitat type with the aid of Quantum GIS, an open source Geographic Information System [18].

This study was conducted from 2013 to 2015, during which time California was experiencing drought conditions (beginning 2011 through 2015). Data on plotspecific habitat, abiotic and environmental variables were collected each year of the study, and chosen based on previous studies $[10,13,15]$. Data loggers, placed in each plot just above ground level and protected from direct solar radiation, collected hourly temperature data during both summer and winter months (iButtons, Maxim Integrated, San Jose CA). From the data loggers, we calculated average maximum and minimum daily temperature over the dry (1 May - 31 October) and rainy (1 November-30 April) seasons. We estimated overstory canopy cover in each plot using satellite imagery derived from Google Earth and processed in Quantum GIS [18], which we subsequently ground-truthed with a convex spherical crown densitometer (Forestry Suppliers, Inc. Jackson MS). 


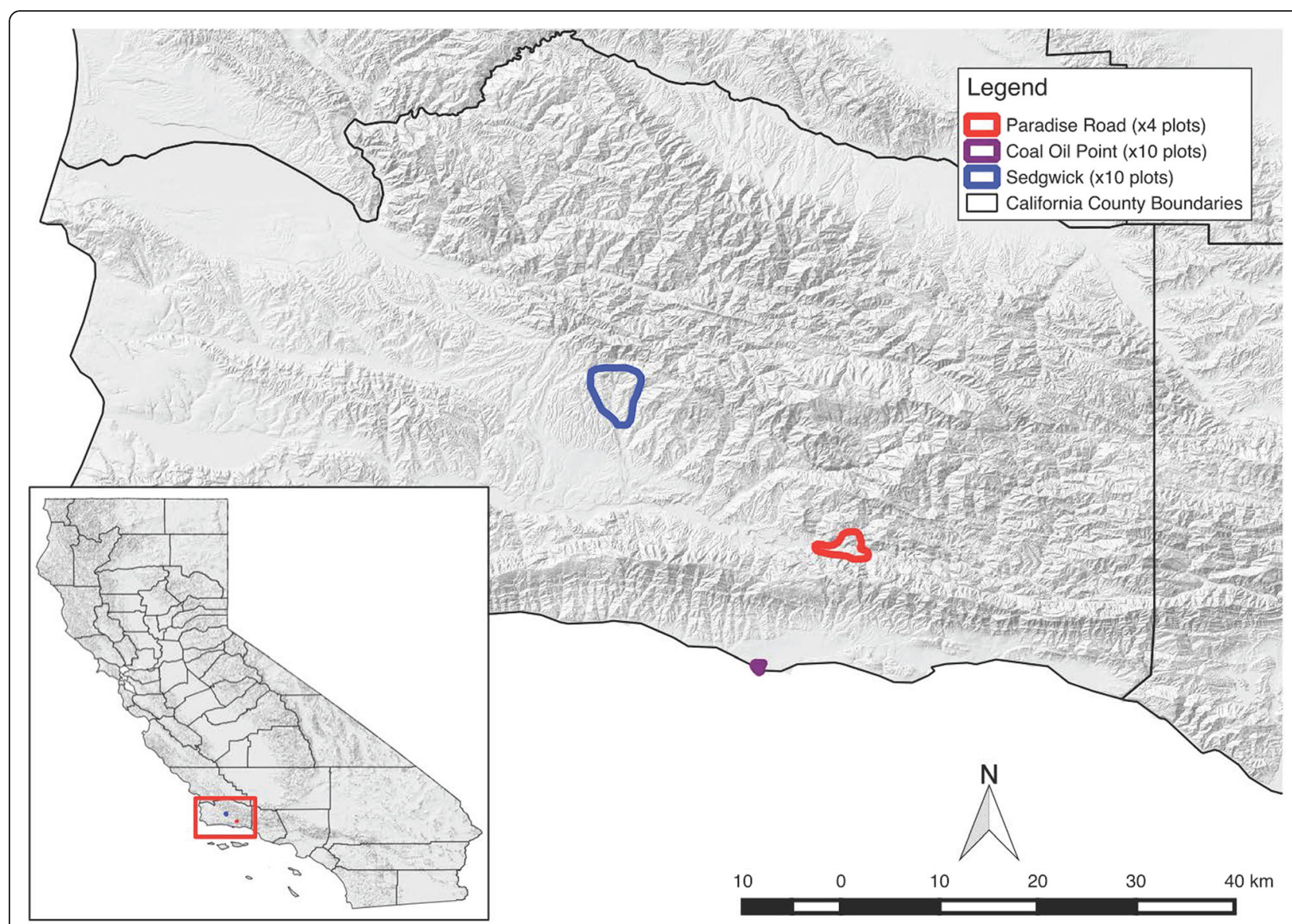

Fig. 1 Map of study sites. State of California is inset on the bottom left; Santa Barbara County is in the main frame with study site boundaries included. California hill shade data layer was obtained from Cal-Atlas through https://koordinates.com (https://koordinates.com/layer/692-california-hillshade-30m/)

We estimated percent cover of leaf litter greater than $5 \mathrm{~cm}$ in depth, grass/herbaceous vegetation, understory woody vegetation (e.g. Artemisia californica, Baccharis pilularis, Toxicodendron diversilobum) and bare ground following the same procedure as above. Additionally, we measured stem density (number of stems greater than $5 \mathrm{~cm}$ in diameter at breast height and greater than $1.5 \mathrm{~m}$ in height), slope and elevation at the center of each plot, as well as density of inhabited dusky-footed woodrat (Neotoma fuscipes) middens [19]. While other species of small vertebrate host are known to be important blood meal hosts for juvenile ticks (e.g. western fence lizards, Sceloporus occidentalis) and pathogen reservoirs (e.g. western gray squirrels, Sciurus griseus), these species were not censused in this study. Instead, woodrat middens were censused because $N$. fuscipes is an important reservoir for B. burgdorferi (s.s.) in California, the nests are conspicuous on the landscape and the density of active nests may be indicative of small vertebrate host availability for the immature stages of $I$. pacificus more generally in this region [20, 21]. Density of inhabited woodrat middens was estimated once each year for each of the 24 plots by counting every active nest within each plot during the spring (March-April) of each year of the study, following Hamm and colleagues [19]. Measurements of relative humidity, while thought to be an important driver of tick survivorship during the summer dry season [13, 14], were not collected at the plot-level. However, weather station data from the region indicate that high summer- and winter-time temperatures are negatively correlated with measures of relative humidity [16], suggesting that plot-level temperature and habitat characteristics alone are a good proxy for this metric of microclimatic conditions.

Questing ticks were collected at each site using the flagging method, in which a $1 \mathrm{~m}^{2}$ white flannel cloth is dragged over understory vegetation and leaf litter, and attached, questing ticks are removed (e.g. [22]). This method is effective for collection of ixodid ticks and provides a proxy for human risk of tick encounter. An area of $500 \mathrm{~m}^{2}$ was sampled on each sampling event in each of the 24 plots, which were sampled weekly to biweekly from late November to early June, the period of seasonal activity for I. pacificus in southern California 
[16] in order to determine both peak and average density of each life stage of I. pacificus in each plot. All 24 plots across the three reserves were sampled during the 2013-2014 and 2014-2015 seasons. All ticks encountered were collected and preserved in $70 \%$ ethanol for species identification and subsequent testing in the lab for infection with B. burgdorferi (sensu lato) (s.l.), the genospecies complex containing the causative agent of Lyme disease.

\section{DNA extraction and pathogen detection}

DNA was extracted from all adult and nymphal Ixodes spp. ticks using a DNeasy blood and tissue kit (Qiagen, Valencia, CA) following the manufacturer's instructions. All tick samples were then screened for infection with spirochetes in the B. burgdorferi (sensu lato) (s.l.) complex, of which B. burgdorferi (s.s.) is a part, via nested polymerase chain reaction (PCR) targeting the 5S-23S rRNA spacer region of all borreliae belonging to this group, following the methods outlined in Lane et al. [23]. PCR-positive samples were sequenced at the 5S-23S intergenic spacer region following Lane et al. [23], on an ABI Prism 3100 Genetic Analyzer (Applied Biosystems, CA).

While I. pacificus is the primary vector of B. burgdorferi (s.s.) to humans, other species of ticks in the genus Ixodes have been implicated in enzootic transmission of various genospecies within the B. burgdorferi (s.l.) complex $[24,25]$. Given the relative dearth of previous studies on Lyme disease ecology in central and southern California, and the low prevalence in vector populations from these few investigations [17, 26], DNA from all adult and nymphal Ixodes spp. ticks was extracted and tested individually for infection with $B$. burgdorferi (s.l.) complex spirochetes.

\section{Statistical analyses}

Habitat and abiotic predictor variables, which were selected a priori based on previous studies [10, 13, 15], were highly collinear in this study, and a comparatively large number of predictor variables of interest were measured relative to the number of observations (i.e. 10 to 13 predictor variables, depending on the model, and 24 sampled plots). To address the problem of multicollinearity and sample size, data dimensionality reduction was necessary in the statistical analyses employed. Partial least squares regression (PLSR) is particularly well suited to addressing these problems and has been shown to perform better than multiple regression or principal components regression techniques in similar ecological data analysis contexts [27].

PLSR generalizes and combines features of principal component analysis and multiple regression to (i) eliminate the problem of multicollinearity in the independent variables $(X)$ that plagues the ordinary multiple regression approach, and (ii) eliminate the problem of choosing an optimum subset of predictors that remains in the principal components regression approach. In principal components regression, orthogonal components are chosen that explain as much of the variance in $X$ as possible, which does not guarantee that the components chosen are relevant to the dependent variable of interest $(\boldsymbol{Y})$ when subsequently used as predictors in a regression framework. In contrast, in PLSR a set of components, or latent vectors, are chosen that explain as much of the covariance between $\boldsymbol{X}$ and $\boldsymbol{Y}$ as possible. This is followed, as in principal components regression, by a regression step in which the set of orthogonal components chosen through the simultaneous decomposition of $\boldsymbol{X}$ and $\boldsymbol{Y}$ are used to predict $\boldsymbol{Y}$.

PLSR models were specified using the abiotic and environmental data described above as predictors, and both peak and average density of adult, nymphal and larval $I$. pacificus ticks as well as infection prevalence (proportion infected) of Ixodes spp. ticks with B. burgdorferi (s.l.) as outcome variables. Environmental data measured in the year prior to tick collection, in addition to data from the year of collection, were included in the models because abundance and infection prevalence of adult and nymphal ticks in year $t$ are largely determined by survivorship and activity of nymphal and larval ticks in year $t-1$, due to the 3-year life-cycle of I. pacificus [13]. Concurrent temperature and relative humidity may also influence tick questing activity [13, 14], so average daily maximum rainy season temperature from the year of collection was also included in all models. Models specified for the first year of the study include only concurrent rainy season temperature, and no measure of lagged summer or winter temperature, because data were not available for the previous year. Models were specified independently for the different years of the study to both investigate the robustness of the core results, as well as to separate natural interannual variation in tick density that might be influenced by variation in environmental conditions from year to year. All statistical analyses were conducted in R 3.2.4 [28], and PLSR models were run using the package 'plsdepot' [29].

\section{Results}

\section{Drivers of tick density}

In total, 765 I. pacificus ticks - 288 adults, 67 nymphs and 410 larvae - were collected over the duration of the study across all 24 plots. In addition, 9 Ixodes spinipalpis, 6 Ixodes peromysci, 178 Ixodes brunneus, 257 Haemaphysalis leporispalustris (rabbit tick), 544 Dermacentor variabilis (American dog tick), and 525 Dermacentor occidentalis (Pacific Coast tick) were collected over the course of the study (Table 1). The large number of I. brunneus, a parasite of migratory and other birds, collected in this study was likely due to the high density and diversity of bird species 
Table 1 Tick species collected by flagging by stage, year and site. Tick species diversity (Shannon's H index) is presented as maximum plot-level diversity with average reserve-level diversity in parentheses

\begin{tabular}{|c|c|c|c|c|c|c|c|c|c|}
\hline Site & Year & $\begin{array}{l}\text { I. pacificus } \\
(A, N, L)\end{array}$ & $\begin{array}{l}\text { I. brunneus } \\
(A, N, L)\end{array}$ & $\begin{array}{l}\text { I. spinipalpis } \\
(A, N, L)\end{array}$ & $\begin{array}{l}\text { I. peromysci } \\
(A, N, L)\end{array}$ & $\begin{array}{l}\text { D. occidentalis } \\
(\mathrm{A}, \mathrm{N}, \mathrm{L})\end{array}$ & $\begin{array}{l}\text { D. variabilis } \\
(A, N, L)\end{array}$ & $\begin{array}{l}\text { H. leporispalustris } \\
(A, N, L)\end{array}$ & $\begin{array}{l}\text { Tick diversity } \\
\text { maximum (average) }\end{array}$ \\
\hline \multirow[t]{2}{*}{ COPR } & 2014 & $31,0,0$ & $1,1,20$ & $0,3,0$ & $0,1,0$ & $0,0,0$ & $390,0,0$ & $1,29,151$ & $1.365(0.315)$ \\
\hline & 2015 & $16,0,0$ & $0,3,152$ & $1,5,0$ & $1,4,0$ & $0,0,0$ & $125,0,0$ & $0,8,33$ & \\
\hline \multirow[t]{2}{*}{ Paradise } & 2014 & $93,32,89$ & $0,0,0$ & $0,0,0$ & $0,0,0$ & $12,1,8$ & $0,0,0$ & $0,0,0$ & $0.414(0.329)$ \\
\hline & 2015 & $61,1,35$ & $0,0,0$ & $0,0,0$ & $0,0,0$ & $17,0,0$ & $0,0,0$ & $0,0,0$ & \\
\hline \multirow[t]{2}{*}{ Sedgwick } & 2014 & $54,8,35$ & $0,0,0$ & $0,0,0$ & $0,0,0$ & $246,15,114$ & $24,0,5$ & $0,7,24$ & $0.982(0.613)$ \\
\hline & 2015 & $33,26,251$ & $1,0,0$ & $0,0,0$ & $0,0,0$ & $26,6,80$ & $0,0,0$ & $0,3,1$ & \\
\hline
\end{tabular}

Abbreviations: $A$ adults, $L$ larvae, $N$ nymphs

documented at Coal Oil Point Reserve (http://coaloilpoint.ucnrs.org/Species/Birds.html) where the majority of the I. brunneus were collected. Both average and peak density of adult and nymphal I. pacificus declined slightly from the 2013-2014 to the 2014-2015 season, though not significantly (Table 2 ). In contrast, average and peak larval I. pacificus density increased slightly, though not significantly, from 2013-2014 to the 20142015 seasons (Table 2). Separate PLSR models were constructed for each tick response variable for each year of the study. Results were remarkably consistent between models predicting peak and average density of adult, nymphal and larval I. pacificus within a given year, due to significant positive correlation between these two measures, so multivariate PLSR models were run with both peak and average tick density as outcome variables in the same model. The results of the multivariate models of tick density, as well as the models predicting infection prevalence are presented here.

In the first year of the study (2013-2014), adult $I$. pacificus density was primarily explained by woodrat nest density and dense oak woodland habitat. Two significant components were extracted in the multivariate model that explained $71.8 \%$ of the original variance in the response variables (Table 3). The first component accounts for a reasonably large proportion of the overall variance $(\sim 45 \%)$, while the second component accounts for a smaller, but significant proportion ( $27 \%)$. The underlying drivers of these two components can be deduced from the variable weights and variable importance in the projection (VIP) scores (Table 3). The sum of squared variable weights for each component is equal to one, so the relative contribution of individual variables to the meaning of each component, and thus to the interpretation of the factors driving tick density, can be estimated [27]. In the multivariate model that predicts average and peak density of adult I. pacificus in 2013-2014, the first component is primarily determined by woodrat nest density ( $43 \%)$, with stem density, canopy cover and elevation all contributing $>10 \%$ of the information content of the first component (Table 3). These four variables are not independent, but rather define an environment/habitat type that can be characterized as dense oak woodland. The significance of woodrat nest

Table 2 Average and peak density of I. pacificus adults, nymphs and larvae in 2013-2014 and 2014-2015 by reserve (site). Densities are presented as number of ticks per $100 \mathrm{~m}^{2}$ with standard errors in parentheses

\begin{tabular}{|c|c|c|c|c|c|}
\hline \multirow[b]{2}{*}{ Life stage } & \multirow[b]{2}{*}{ Site } & \multicolumn{2}{|c|}{ Average density } & \multicolumn{2}{|l|}{ Peak density } \\
\hline & & 2013-2014 & 2014-2015 & 2013-2014 & 2014-2015 \\
\hline \multirow[t]{3}{*}{ Adults } & COPR & $0.017(0.009)$ & $0.005(0.003)$ & $0.1(0.045)$ & $0.06(0.031)$ \\
\hline & Paradise & $0.568(0.147)$ & $0.615(0.164)$ & $1.25(0.210)$ & $1.3(0.520)$ \\
\hline & Sedgwick & $0.039(0.009)$ & $0.027(0.011)$ & $0.28(0.074)$ & $0.208(0.060)$ \\
\hline Adults total & & $0.118(0.047)$ & $0.115(0.053)$ & $0.367(0.096)$ & $0.328(0.122)$ \\
\hline \multirow[t]{3}{*}{ Nymphs } & COPR & $0(0)$ & $0(0)$ & $0(0)$ & $0(0)$ \\
\hline & Paradise & $0.109(0.050)$ & $0.007(0.007)$ & $0.359(0.123)$ & $0.036(0.036)$ \\
\hline & Sedgwick & $0.007(0.004)$ & $0.025(0.018)$ & $0.06(0.031)$ & $0.147(0.102)$ \\
\hline Nymphs total & & $0.021(0.011)$ & $0.012(0.008)$ & $0.085(0.034)$ & $0.067(0.044)$ \\
\hline \multirow[t]{3}{*}{ Larvae } & COPR & $0(0)$ & $0(0)$ & $0(0)$ & $0(0)$ \\
\hline & Paradise & $0.297(0.175)$ & $0.201(0.150)$ & $0.959(0.389)$ & $0.6(0.356)$ \\
\hline & Sedgwick & $0.024(0.024)$ & $0.275(0.204)$ & $0.38(0.38)$ & $1.953(1.311)$ \\
\hline Larvae total & & $0.06(0.036)$ & $0.148(0.089)$ & $0.318(0.178)$ & $0.914(0.564)$ \\
\hline
\end{tabular}


Table 3 PLSR Model results for multivariate adult I. pacificus average and peak density in 2013-2014 and 2014-2015. VIP scores greater than 1 (highlighted in bold) indicate significant contributions of those variables to the variation explained by each component; variable weights indicate the direction of the effect. Asterisk indicates the variable contributing most significantly to the variation in the component, and the strongest predictor of tick density. The second component acts on residual variation not explained by the first component

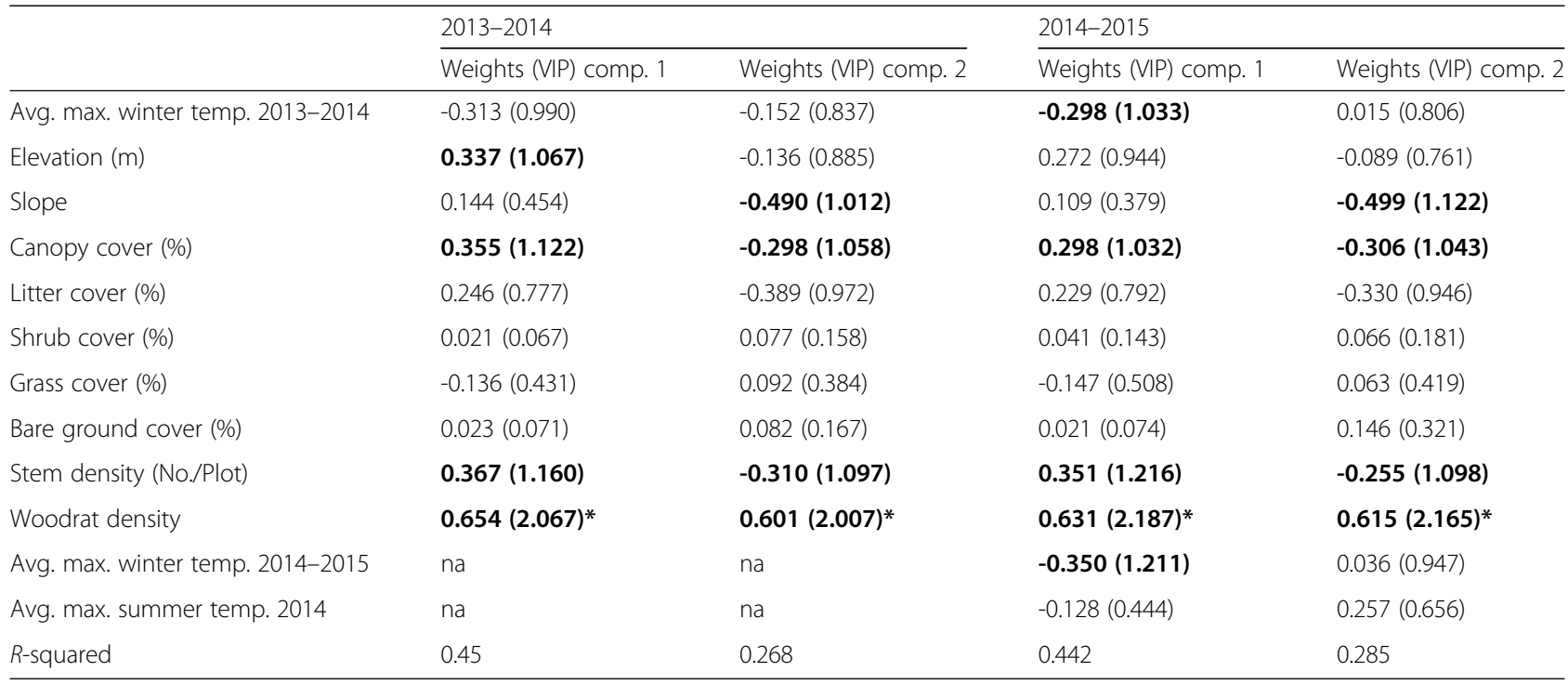

Abbreviations: na not available, VIP variable importance in the projection

density here also suggests that host availability is an important driver of this first component. The VIP scores, which are calculated as the weighted sum of squares of the PLS weights, taking into account the explained variance of each PLS component, confirm that these same four variables (woodrat density, stem density, canopy cover and elevation) drive the relationship between the first component and adult tick density. The correlation between average and peak adult tick density in 2013-2014 and the position of the 24 plots in the first component of this PLSR model are shown in Fig. 2a, b $(r=0.592, P<$ 0.01 ; and $r=0.707, P<0.0001$, respectively). The second component is applied to the residual variation not explained by the first component, illustrated in Fig. 2c, d $(r=0.742, P<0.0001$; and $r=0.592, P<0.01$, respectively). Variable weights and VIP scores indicate that the residual variation in adult tick density is primarily explained by woodrat density, as well as a negative association with slope, canopy cover and stem density (Table 3). This set of explanatory variables suggests an association with both forested and more open grassland/chaparral habitats, which may be indicative of an association with the forest edge ecotone. Additionally, the significance of woodrat nest density may indicate the importance of juvenile tick host availability in predicting adult tick density.

Similarly, in the second year of the study adult I. pacificus density was again explained by woodrat nest density and dense oak woodland habitat. The multivariate model of average and peak adult tick density the following year, in 2014-2015, yielded 2 significant components explaining
$72.8 \%$ of the variance in the outcome variables ( 44 and $\sim 29 \%$ for component 1 and 2, respectively). VIP scores indicate that woodrat density, stem density and a negative association with average daily maximum rainy season temperature in the year of tick collection are driving the relationship between the first component and adult tick density in 2014-2015 (Table 3). Again, the residual variation is primarily explained by woodrat density, as well as a negative association with slope, stem density and canopy cover (Table 3). The multivariate PLSR models of average and peak adult $I$. pacificus density specified for each year of the study thus yielded remarkably consistent results.

The variables that explained patterns of nymphal tick density in 2013-2014 were similar to those of adult ticks, with woodrat density and dense oak woodland habitat driving the relationship. However, woodrat density was no longer a significant predictor in the second year of study, with variables associated with dense oak woodland driving the relationship. Results of the multivariate models of average and peak nymphal I. pacificus density were not as strong as those predicting adult tick density and not as consistent between the 2 years of the study. In 2013-2014, 2 extracted components explained $66 \%$ of the variation in the outcome variables $(\sim 48$ and $\sim 18 \%$ by component 1 and 2, respectively). VIP scores indicate that woodrat density, stem density and canopy cover are driving the relationship between the first component and nymphal tick density (Table 4; Fig. 3). The residual variation is primarily explained by woodrat nest density, bare ground cover, as well as negative 

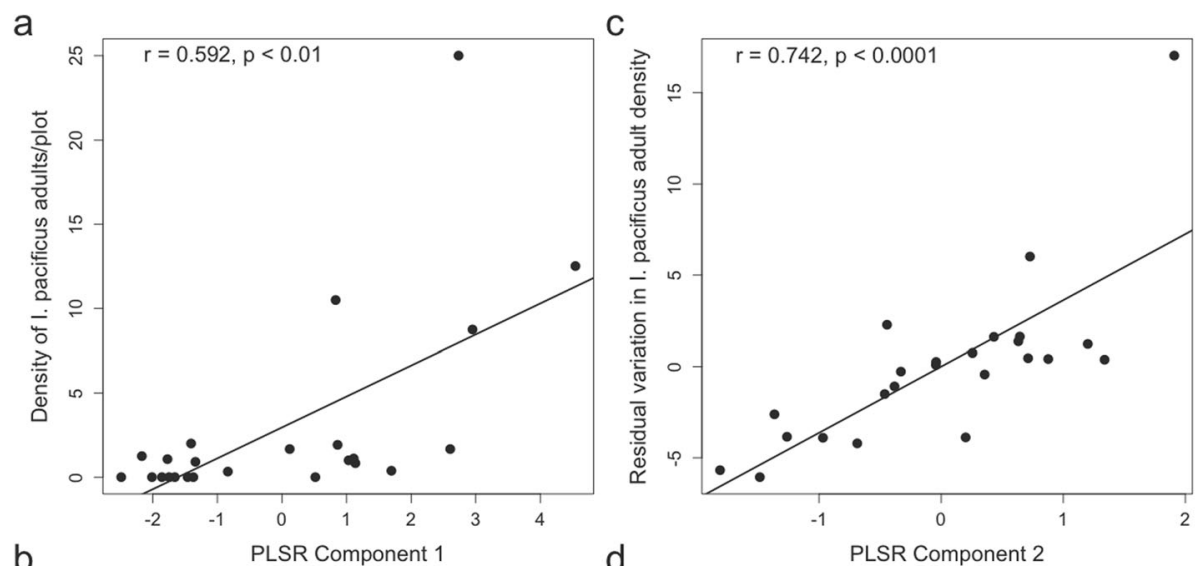

b

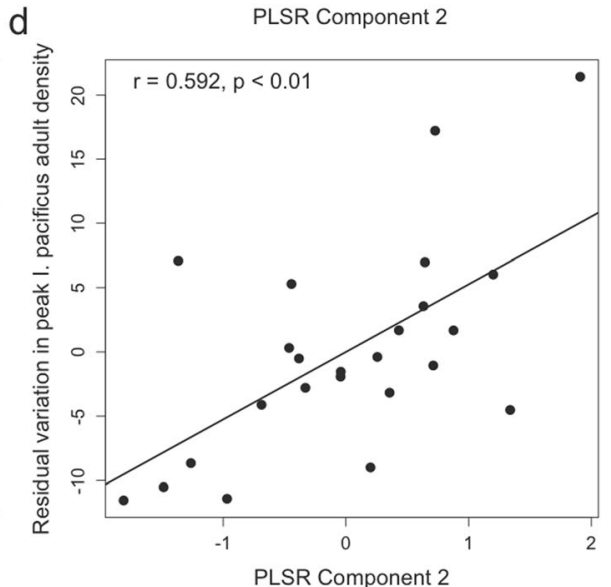

Fig. 2 Density (a) and peak density (b) of adult I. pacificus in 2013-2014 plotted against the position of each sampled plot in the first PLSR component; and residual variation in density (c) and residual variation in peak density (d) plotted against the position of each sampled plot in the second PLSR component. Correlation coefficients and P-values are presented in each panel

Table 4 PLSR Model results for multivariate nymphal I. pacificus average and peak density in 2013-2014 and 2014-2015. VIP scores greater than 1 (highlighted in bold) indicate significant contributions of those variables to the variation explained by each component; variable weights indicate the direction of the effect. Asterisk indicates the variable contributing most significantly to the variation in the component, and the strongest predictor of tick density. The second component acts on residual variation not explained by the first component

\begin{tabular}{|c|c|c|c|c|}
\hline & \multicolumn{2}{|l|}{ 2013-2014 } & \multicolumn{2}{|l|}{$2014-2015$} \\
\hline & Weights (VIP) comp. 1 & Weights (VIP) comp. 2 & Weights (VIP) comp. 1 & Weights (VIP) comp. 2 \\
\hline Avg. max. winter temp. 2013-2014 & $-0.187(0.590)$ & $0.081(0.522)$ & $0.021(0.073)$ & $0.377(0.882)$ \\
\hline Elevation (m) & $0.312(0.986)$ & $-0.237(0.929)$ & $0.313(1.083)$ & $-0.162(0.885)$ \\
\hline Slope & $0.071(0.223)$ & $-0.637(1.059)$ & $0.228(0.789)$ & $-0.238(0.806)$ \\
\hline Canopy cover (\%) & $0.386(1.220)$ & $-0.225(1.107)$ & $0.307(1.063)$ & $-0.308(1.065)$ \\
\hline Litter cover (\%) & $0.299(0.946)$ & $-0.278(0.929)$ & $0.706(2.445)^{*}$ & $0.403(2.036)^{*}$ \\
\hline Shrub cover (\%) & $0.055(0.173)$ & $0.116(0.241)$ & $0.007(0.026)$ & $0.005(0.023)$ \\
\hline Grass cover (\%) & $-0.235(0.742)$ & $-0.082(0.649)$ & $-0.317(1.098)$ & $-0.184(0.918)$ \\
\hline Bare ground cover (\%) & $0.249(0.788)$ & $0.534(1.104)$ & $-0.068(0.235)$ & $-0.025(0.183)$ \\
\hline Stem density (No./Plot) & $0.470(1.485)$ & $-0.043(1.273)$ & $0.365(1.266)$ & $-0.234(1.082)$ \\
\hline Woodrat density & $0.533(1.686)^{*}$ & $0.310(1.529)^{*}$ & $0.121(0.419)$ & $-0.413(1.013)$ \\
\hline Avg. max. winter temp. 2014-2015 & na & na & $-0.063(0.218)$ & $0.372(0.885)$ \\
\hline Avg. max. summer temp. 2014 & na & na & $0.017(0.059)$ & $0.346(0.809)$ \\
\hline$R$-squared & 0.484 & 0.177 & 0.295 & 0.247 \\
\hline
\end{tabular}



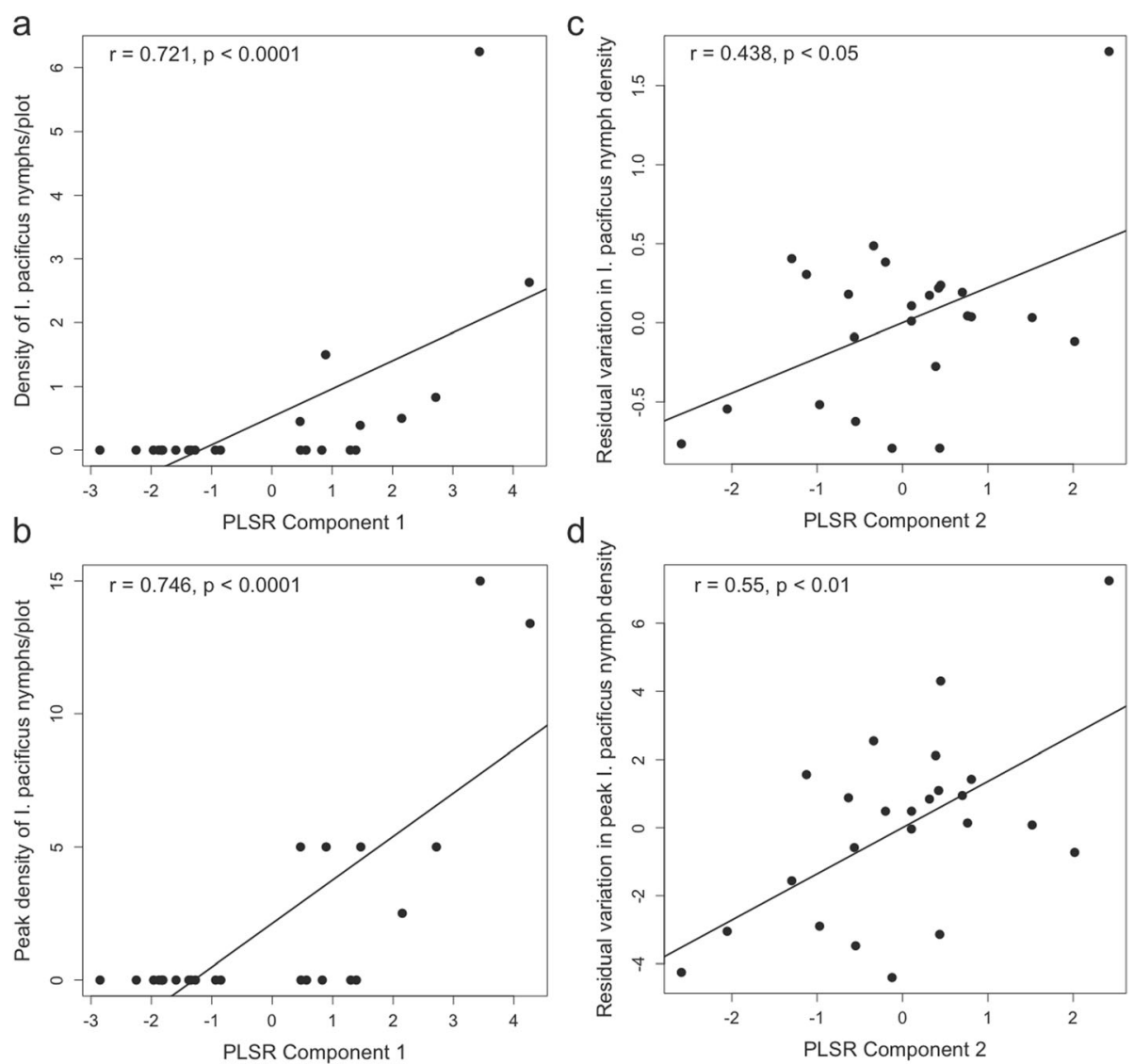

Fig. 3 Density (a) and peak density (b) of nymphal I. pacificus in 2013-2014 plotted against the position of each sampled plot in the first PLSR component; and residual variation in density (c) and residual variation in peak density (d) plotted against the position of each sampled plot in the second PLSR component. Correlation coefficients and $P$-values are presented in each panel

associations with stem density, slope and canopy cover. In the second year of the study, 2 extracted components explained only $54 \%$ of the variation in average and peak nymphal tick density ( $\sim 30$ and $\sim 25 \%$ by component 1 and 2, respectively). The VIP scores indicate that woodrat density was no longer a significant predictor in 2014-2015, instead percent leaf litter cover was the strongest predictor with stem density, canopy cover, elevation and a negative association with grass/herbaceous cover also contributing to the relationship between the first component and nymphal tick density (Table 4). Residual variation was explained primarily by leaf litter cover, as well as negative associations with woodrat density, stem density and canopy cover (Table 4).

The models of larval I. pacificus density show remarkably similar patterns to models of nymphal ticks, suggesting immature stages responded similarly to abiotic conditions in this study. In 2013-2014, 2 extracted components explained $48 \%$ of the variation in the outcome variables ( $\sim 0$ and $\sim 8 \%$ by component 1 and 2 , respectively). VIP scores indicate that woodrat density, stem density, canopy cover, leaf litter cover, as well as negative associations with grass cover are driving the relationship between the first component and larval tick density (Table 5; Fig. 4). The residual variation is primarily explained by woodrat nest density, as well as negative associations with leaf litter cover, canopy cover, grass cover and stem density. In the second year of the study, 2 extracted components explained $63 \%$ of the variation in larval tick density ( 36 and $\sim 27 \%$ by component 1 and 2 , respectively). The VIP scores again indicate that woodrat density was no longer a significant predictor in 2014-2015, instead percent leaf litter cover was the strongest predictor with stem density, canopy cover, elevation and a negative association with grass/herbaceous cover also contributing to the relationship between the first component and larval tick density (Table 5). Residual variation was explained primarily by leaf litter cover, as well as negative associations with stem density, grass cover and canopy cover (Table 5).

\section{Drivers of infection prevalence}

Infection with Borrelia burgdorferi (s.l.) was extremely uncommon throughout the study area (Table 6). No $I$. 
Table 5 PLSR Model results for multivariate larval I. pacificus average and peak density in 2013-2014 and 2014-2015. VIP scores greater than 1 (highlighted in bold) indicate significant contributions of those variables to the variation explained by each component; variable weights indicate the direction of the effect. Asterisk indicates the variable contributing most significantly to the variation in the component, and the strongest predictor of tick density. The second component acts on residual variation not explained by the first component

\begin{tabular}{|c|c|c|c|c|}
\hline & \multicolumn{2}{|l|}{$2013-2014$} & \multicolumn{2}{|l|}{$2014-2015$} \\
\hline & Weights (VIP) comp. 1 & Weights (VIP) comp. 2 & Weights (VIP) comp. 1 & Weights (VIP) comp. 2 \\
\hline Avg. max. winter temp. 2013-2014 & $-0.178(0.561)$ & $0.112(0.533)$ & $-0.017(0.057)$ & $0.395(0.895)$ \\
\hline Elevation (m) & $0.281(0.890)$ & $-0.258(0.878)$ & $0.304(1.054)$ & $-0.123(0.849)$ \\
\hline Slope & $0.124(0.391)$ & $-0.647(0.901)$ & $0.214(0.741)$ & $-0.254(0.804)$ \\
\hline Canopy cover (\%) & $0.351(1.111)$ & $-0.281(1.078)$ & $0.311(1.078)$ & $-0.293(1.052)$ \\
\hline Litter cover (\%) & $0.446(1.411)$ & $-0.048(1.292)$ & $0.674(2.335)^{*}$ & $0.443(2.032)^{*}$ \\
\hline Shrub cover (\%) & $0.155(0.491)$ & $0.287(0.580)$ & $0.056(0.194)$ & $0.049(0.184)$ \\
\hline Grass cover (\%) & $-0.356(1.126)$ & $-0.315(1.106)$ & $-0.343(1.189)$ & $-0.238(1.049)$ \\
\hline Bare ground cover (\%) & $0.046(0.145)$ & $0.381(0.504)$ & $-0.088(0.306)$ & $-0.054(0.261)$ \\
\hline Stem density (No./Plot) & $0.438(1.385)$ & $-0.046(1.268)$ & $0.372(1.289)$ & $-0.215(1.090)$ \\
\hline Woodrat density & $0.455(1.438)^{*}$ & $0.305(1.371)^{*}$ & $0.176(0.609)$ & $-0.365(0.946)$ \\
\hline Avg. max. winter temp. 2014-2015 & na & na & $-0.101(0.351)$ & $0.377(0.895)$ \\
\hline Avg. max. summer temp. 2014 & na & na & $-0.043(0.150)$ & $0.312(0.716)$ \\
\hline$R$-squared & 0.398 & 0.078 & 0.359 & 0.267 \\
\hline
\end{tabular}

Abbreviations: na not available, VIP variable importance in the projection

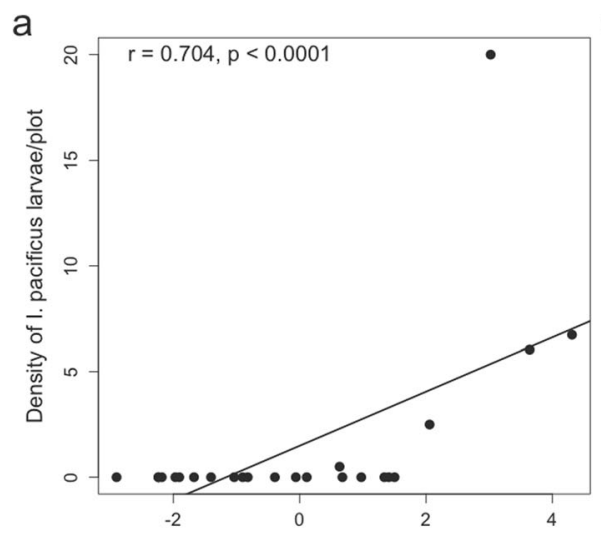

b

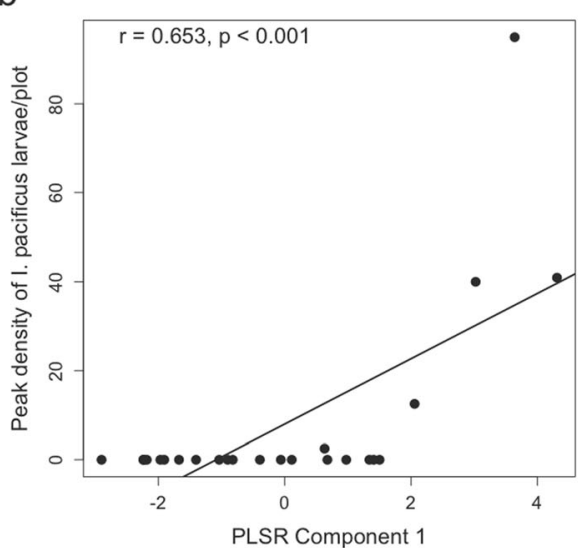

C

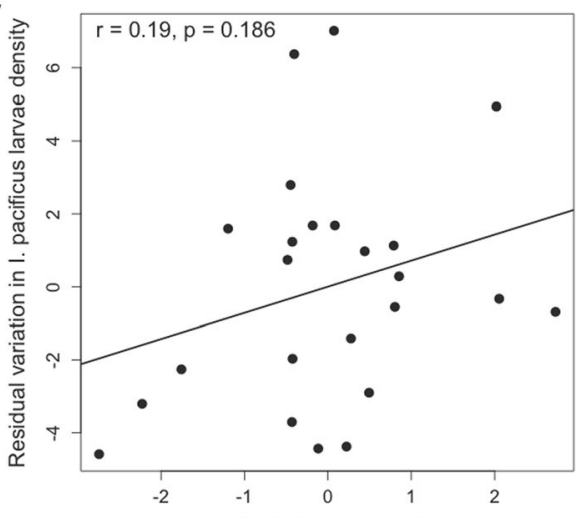

$\mathrm{d}$

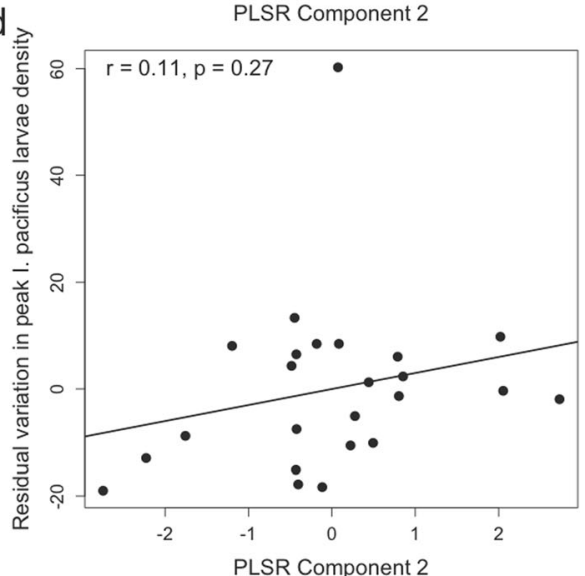

Fig. 4 Density (a) and peak density (b) of larval I. pacificus in 2013-2014 plotted against the position of each sampled plot in the first PLSR component; and residual variation in density (c) and residual variation in peak density (d) plotted against the position of each sampled plot in the second PLSR component. Correlation coefficients and $P$-values are presented in each panel 
Table 6 Summary of infection results by tick species

\begin{tabular}{lllll}
\hline Tick species & Number tested & Number infected & B. burgdorferi (s.l.) type & Prevalence (\%) (all life stages) \\
\hline I. pacificus & 288 adults; 67 nymphs & 0 & na & na \\
I. brunneus & 2 adults; 4 nymphs & 0 & na & na \\
I. spinipalpis & 1 adult; 8 nymphs & 1 adult female & B. bissettiae & 11.1 \\
I. peromysci & 1 adult; 5 nymphs & 3 nymphs & B. burgdorferi (s.s.) (1); B. bissettiae (2) & 50.0 \\
\hline
\end{tabular}

Abbreviation: na not available

pacificus, the primary vector of B. burgdorferi (s.s.) to humans in the western US, were infected with any spirochete in the B. burgdorferi (s.l.) complex out of 288 adults and 67 nymphs that were tested in this study. However, there was evidence that other Ixodes spp. ticks in this region may be positive for infection with B. burgdorferi (s.s.), the causative agent of Lyme disease, as well as with Borrelia bissettiae, another spirochete in the $B$. burgdorferi (s.l.) complex that may be involved in Lyme borreliosis in central and southern Europe [30-32]. Borrelia bissettiae has also been isolated from ticks and hosts throughout the US [33], and DNA resembling $B$. bissettiae has been isolated from the serum of a Lyme disease patient in northern California [34], though illness

Table 7 PLSR Model results for infection prevalence with Borrelia burgdorferi (s.l.) in Ixodes spp. ticks, 2014-2015. VIP scores greater than 1 (highlighted in bold) indicate significant contributions of those variables to the variation explained by each component; variable weights indicate the direction of the effect. Asterisk indicates the variable(s) contributing most significantly to the variation in the component, and the strongest predictor of infection. The second component acts on residual variation not explained by the first component

\begin{tabular}{|c|c|c|}
\hline & $\begin{array}{l}\text { Weights (VIP) } \\
\text { comp. } 1\end{array}$ & $\begin{array}{l}\text { Weights (VIP) } \\
\text { comp. } 2\end{array}$ \\
\hline $\begin{array}{l}\text { Avg. max. winter temp. } \\
\text { 2013-2014 }\end{array}$ & $-0.040(0.144)$ & $0.442(1.594)^{*}$ \\
\hline Elevation (m) & $-0.278(1.001)$ & $-0.025(0.092)$ \\
\hline Slope & $-0.103(0.373)$ & $-0.186(0.670)$ \\
\hline Canopy cover (\%) & $-0.091(0.328)$ & $-0.239(0.861)$ \\
\hline Litter cover (\%) & $0.123(0.443)$ & $-0.211(0.761)$ \\
\hline Shrub cover (\%) & $0.156(0.561)$ & $-0.373(1.344)$ \\
\hline Grass cover (\%) & $-0.144(0.518)$ & $0.381(1.375)$ \\
\hline Bare ground cover (\%) & $-0.296(1.068)$ & $0.311(1.120)$ \\
\hline Stem density (No./Plot) & $-0.065(0.234)$ & $-0.202(0.729)$ \\
\hline Woodrat density & $-0.144(0.518)$ & $-0.185(0.667)$ \\
\hline Tick diversity (Shannon's) & $0.603(2.174)^{*}$ & $0.224(0.807)$ \\
\hline $\begin{array}{l}\text { Avg. max. winter temp. } \\
\text { 2014-2015 }\end{array}$ & $0.012(0.044)$ & $0.401(1.446)$ \\
\hline $\begin{array}{l}\text { Avg. max. summer temp. } \\
2014\end{array}$ & $-0.605(2.181)^{*}$ & $-0.034(0.124)$ \\
\hline$R$-squared & 0.529 & 0.086 \\
\hline
\end{tabular}

Abbreviation: VIP variable importance in the projection associated with $B$. bissettiae in North America is not well established. Specifically, in this study three of six (50\%) Ixodes peromysci tested were positive for B. burgdorferi (s.l.), all from Coal Oil Point Reserve (Fig. 1). Ixodes peromysci is a specialist on deer mice (Peromyscus maniculatus) and other small rodents [35]. In this study, one nymph was infected with B. burgdorferi (s.s.) and two nymphs were infected with $B$. bissettiae (Table 6). In addition, one out of nine (11\%) Ixodes spinipalpis tested was positive for B. burgdorferi (s.l.), again from Coal Oil Point Reserve. Ixodes spinipalpis is thought to play a role in the enzootic maintenance of B. burgdorferi (s.l.) in California $[24,25]$ and one adult female was found to be infected with B. bissettiae in this study (Table 6). However, both of these species of tick very rarely bite humans, so present very little risk of human infection.

Due to the lack of infection in ticks in 2013-2014, PLSR models predicting infection were performed only for the 2014-2015 season and were not run for I. pacificus, which were not infected in this study. In addition to the environmental and habitat variables used in the models that predicted tick density, tick species diversity (Shannon's H) was included in the set of predictors for the model of infection prevalence (Tables 1 and 7). The two extracted components explained $62 \%$ of the variation in infection prevalence ( 53 and $~ 9 \%$ by component 1 and 2, respectively). In contrast to models that predicted density of I. pacificus, VIP scores indicate that infection prevalence in the tick community was most strongly influenced by vector diversity and both summer and winter temperature, rather than by woodrat density or dense oak woodland. There was a strong positive association between tick diversity and infection prevalence with B. burgdorferi (s.l.) spirochetes in the tick community (Table 7). In addition, there was a strong negative association with maximum summer temperature, and positive association with maximum winter temperature (Table 7).

\section{Discussion}

In order to better understand and manage risk of vectorborne and zoonotic disease an understanding of the environmental conditions that promote vector populations and infection prevalence with zoonotic pathogens on the landscape is increasingly necessary $[2,5-7,36]$. In northwestern California, the region of western North America with 
the highest human incidence of Lyme disease [37], the abiotic, habitat and environmental conditions that might promote vector density and infection prevalence have been investigated in numerous studies $[10,11,13-15$, 38-40]. While there is substantial natural heterogeneity in density and infection prevalence of I. pacificus in California, both over space and through time $[9,15]$, these previous studies have largely identified dense oak woodlands with microclimates that maintain high relative humidity and small temperature fluctuations, particularly in the summer months, as high-risk areas for Lyme disease $[10,11,13-15,38-40]$. In southern California, one of the most densely populated regions of the US, Lyme disease ecology and environmental risk factors have not been well explored, though there is evidence to suggest the ecology and epidemiology of the disease may differ from northwestern California $[16,17]$.

In this study, density of I. pacificus ticks across all life stages, particularly the nymphal stage, and across all plots and years sampled was very low compared to previous density estimates from similar studies conducted in northwestern California [15, 41]. For example, previous estimates of peak adult density in northern California range from $\sim 15$ to $\sim 380$ ticks per $100 \mathrm{~m}^{2}$ [41] compared to $<1$ in the present study to $\sim 3$ ticks per $100 \mathrm{~m}^{2}$ in a recent study conducted in southern California [16], with similar patterns observed for nymphal and larval ticks. This may be due in part to the worsening drought conditions experienced in California over the course of the present study, which would obscure direct comparison with earlier studies conducted in northern California in the absence of baseline data from southern California. However, this may also suggest actual differences in baseline density of $I$. pacificus between these two regions. For example, a previous study [17] found nymphal density to be extremely low in southern California in years prior to the recent drought. Furthermore, interannual patterns of nymphal and adult tick density in southern California suggest a significant difference in questing behavior of this life stage between northwestern and southern California.

Adult tick density in year $t$ should be determined by nymphal tick density in year $t-1$, yet questing nymphal tick density in year $t-1$ is substantially lower than adult tick density in year $t$ in both the present study as well as in a recent study conducted in southern California [16]. This hourglass-shaped demographic distribution, with much higher densities of adult and larval ticks than nymphal ticks, contrasts with the expected pyramidshaped distribution found in other studies in northern California [41]. This curious demographic pattern suggests that nymphal ticks are not being captured at the same rate by the flagging method in southern California as they are in northern California, which may indicate a regional difference in questing behavior of this stage similar to patterns observed in the southeastern US with nymphal I. scapularis [42]. In the northeastern US all life stages of $I$. scapularis are readily collected by flagging, while in the southeast the same method collects very few juvenile stages, even at sites where adults are readily collected [42]. A recent study investigated whether this may be due to differences in nymphal $I$. scapularis questing behavior between northern and southern populations, and found strong evidence suggesting that nymphal I. scapularis from southern populations rarely emerge from leaf litter to quest for hosts, while nymphs from northern populations do [42]. This behavioral difference has significant implications for disease transmission to humans [42], and may also be characteristic of populations of I. pacificus in western North America.

In this study, the abiotic and environmental drivers of variation in tick density and infection prevalence in southern California were investigated using a partial least squares regression approach. Results from models predicting adult $I$. pacificus density were consistent across years and suggest that host availability for juvenile ticks was the most significant factor predicting adult tick density (i.e. VIP scores were substantially higher for woodrat density in both extracted components than for other significant predictors). Dense oak woodland and concurrent average daily maximum rainy season temperature were also found to be important drivers of adult tick density, as predicted, though not as strong as host availability for juvenile $I$. pacificus. While the possibility exists that oak woodland habitat may be a driver of both tick and woodrat abundance, particularly in some regions of California, in this study woodrats were abundant in both chaparral- and oak woodland-dominated plots suggesting that the relationship between woodrat abundance and tick abundance is likely not due to a spurious correlation. The significance of rainy season temperature, concurrent with tick questing, for adult I. pacificus density suggests that high rainy season temperatures may inhibit adult tick questing activity. Rainy season temperatures may be as significant as summer dry season conditions and average maximum daily temperature in the previous summer $[13,15]$ in determining the likelihood of encountering adult $I$. pacificus ticks in southern California, and suggests that winter temperatures may also be an important limitation on adult tick populations.

Results from models predicting both nymphal and larval I. pacificus density were less consistent between years, and explained less of the variation in tick density than did models for adult tick density. This may have been due to sampling bias for these life stages, since comparatively few larval and nymphal ticks were collected in this study, as in previous studies conducted in southern California [16, 17]. Additionally, variables that 
were not measured in this study, such as the density of western fence lizards, may be relatively more important for juvenile ticks than adult ticks in determining abundance. Omission of such predictor variables could weaken inference on the included predictor variables. In the first year of the study, results suggest that host availability for juvenile ticks was the strongest predictor of both nymphal and larval density, with variables characteristic of dense oak woodland also found to be significant predictors. However, in the second year of the study leaf litter cover was the strongest predictor of both nymphal and larval density, and host availability for juvenile ticks was no longer significant. This may suggest that as drought conditions worsened in California from 2013 through 2015, habitat characteristics - like dense leaf litter and overstory canopy - that promote the microclimatic conditions necessary for tick survivorship (i.e. lower temperatures and higher relative humidity) became more important than host availability as predictors of larval and nymphal tick density.

The finding that no $I$. pacificus ticks were infected with B. burgdorferi (s.l.) spirochetes in this study suggests that human risk of Lyme disease in this region is exceedingly low. However, the identification of infected I. spinipalpis and I. peromysci ticks, both of which very rarely bite humans, is significant. This finding suggests that despite possible enzootic transmission of the pathogen, populations of I. pacificus in southern California are not interacting with enzootic transmission cycles, leading to low human risk. Perhaps this lack of infection in I. pacificus populations is the result of low rates of blood feeding on reservoir hosts relative to non-competent hosts like western fence lizards (S. occidentalis). It may also be due to small sample sizes, particularly of the nymphal stage $(n=67)$, which would make identification of infected I. pacificus unlikely if rates of infection are low. The exact mechanism behind this pattern of infection warrants further investigation, but suggests that pathogen transmission to humans through the bite of infected I. pacificus ticks in this region is highly unlikely. This pattern of infection may also suggest that enzootic transmission of B. burgdorferi (s.l.) in natural transmission cycles involving alternative vector species, other than I. pacificus, and reservoir hosts may be occurring more widely in California than studies focused on the northwestern region of the state might suggest. This may be particularly relevant in the comparatively understudied central and south coastal regions of the state. However, these particular tick species and associations with $B$. burgdorferi (s.l.) genospecies require further investigation, including transmission experiments, to determine whether these results are truly indicative of novel enzootic transmission cycles.

Results also suggest that diversity in the vector community may predict infection prevalence in tick populations, and perhaps in the host community as a result. In this study, low diversity vector communities were comprised of common generalist species like I. pacificus and $D$. occidentalis, while higher diversity communities included both common generalist species as well as less common specialists like I. brunneus, I. spinipalpis and I. peromysci. The higher diversity communities thus included alternative vector species thought to contribute to enzootic maintenance of B. burgdorferi (s.l.), explaining the relationship between vector diversity and infection prevalence in this region and this particular study. The identity of the tick species present in each community sampled was thus critically important in determining the presence of $B$. burgdorferi (s.l.), suggesting that tick species identity rather than species diversity, per se, may be the key factor associated with infection prevalence in this region of California. Additionally, due to the lack of explanatory power of dusky-footed woodrat density for infection prevalence in ticks, this suggests that alternative reservoir hosts, like western gray squirrels or deer mice, may be playing a more important role in the enzootic transmission of tick-borne borreliae in southern California. The significant negative relationship between maximum summer temperature and infection prevalence further corroborates the results of earlier studies suggesting that microclimates characterized by high relative humidity and small temperature fluctuations are more likely to harbor infected ticks in California. This also suggests that the protracted drought in California is negatively impacting tick populations and disease risk. However, due to the comparative rarity of infection in the vector community in this study, it is possible that unmeasured explanatory factors (e.g. host community composition) may be important in determining infection prevalence or whether these pathogens have arrived or could be maintained in particular sites where they were found to be absent.

The results of this study, in addition to identifying possible abiotic and environmental risk factors for Lyme disease in southern California, may have implications for tick-borne disease risk in the western US under climate change. Evidence suggests that the geographic range of the vector in the eastern US, I. scapularis, is increasing as a result of climate change, driving increases in regional Lyme disease risk [43-47]. This is likely due to increases in the basic reproductive number, $R_{0}$, of the vector, resulting from increased molting success and survivorship and accelerated phenology of $I$. scapularis due to milder winters [46]. However, it is currently unknown whether Lyme disease foci in the western US will experience similar range shifts and changes in Lyme disease risk due to climate change. While growth and survival of I. scapularis appears to be limited primarily by winter conditions, I. pacificus, the primary Lyme disease vector 
in the western US, in contrast is largely limited by abiotic conditions in the summer dry season $[10,13,15]$. The results of this study further substantiate the importance of habitat and abiotic conditions that create microclimates that protect desiccation prone ticks from high temperatures and low relative humidity, as well as promote the necessary host populations for maintenance of B. burgdorferi (s.l.) in enzootic transmission cycles. Moreover, in this study it appears that these factors were increasingly important as California's historic drought progressed. In California, temperatures are expected to increase, and precipitation decrease into the future, particularly in northern coastal California [48, 49], exacerbating seasonal drought. We hypothesize that these expected climate change impacts may then serve to limit I. pacificus populations, leading to reduced human risk in California, though may also serve to increase risk in the northwestern US on the northern edge of the Lyme disease foci in western North America. However, the 2 years of data in this study are not sufficient to draw concrete conclusions, and further study of this relationship is necessary to identify the direct effect of climate change on tick populations. Furthermore, the response of the pathogen to climate change, through altered replication rates or interactions between reservoir hosts and competent vectors, also remains uncertain.

\section{Conclusions}

In this study, dense oak woodland habitat and abundant small vertebrate hosts were found to be the strongest predictors of I. pacificus tick abundance, particularly the nymphal stage. However, overall density of $I$. pacificus was found to be quite low in comparison to well-studied sites in northwestern California [15, 41]. Furthermore, habitat types and microclimatic conditions thought to buffer juvenile ticks from desiccation over the summer dry season were found to be increasingly important as the study, and California's historic drought, progressed. These results suggest that drought in California may act as an important limiting factor on I. pacificus populations though further investigation is necessary. Additionally, infection prevalence with B. burgdorferi (s.l.) was exceedingly low or zero across all plots sampled in this study, in contrast with northwestern California. However, despite the low risk of human Lyme disease infection posed by I. pacificus in southern California, comparatively high rates of infection were detected in other Ixodes spp. ticks. While I. spinipalpis and I. peromysci may be playing a role in enzootic transmission of B. burgdorferi (s.l.) in southern California, these species do not commonly bite humans and thus pose little risk for human infection. However, the roles of these tick species in enzootic transmission cycles, and whether $I$. pacificus might be involved, require further investigation.
Finally, infection prevalence was not associated with habitats characterized by oak woodland nor with the presence of dusky-footed woodrats in this study, which suggests that different vector species and reservoir hosts may be playing a key role in the ecology of the transmission cycle in this region.

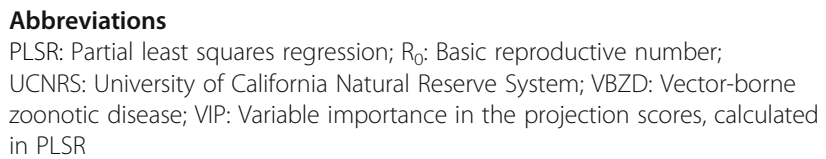

\section{Acknowledgements}

We would like to thank Dr. Hillary Young, Dr. Tom Dudley and three anonymous reviewers for their thorough comments and suggestions, which substantially improved the quality of this manuscript. We would also like to thank Dr. Kevin Lafferty and Dr. Cris Sandoval for access to the Paradise Reserve field site as well as the UC Natural Reserve System for access to the Sedgwick and Coal Oil Point Reserve field sites. We thank Tyler Toth, Narek Ohanian, Sarah Russ, Negeen Izadian, Aybuke Koyuncu and Kelsie Bogyo for help in the field. Finally, we thank Ashley Larsen for helpful comments, direction and support.

\section{Funding}

We are grateful to the UC Natural Reserve System Mildred E. Mathias Grant (to AJM), and Department of Ecology, Evolution and Marine Biology block grant (to AJM) for providing funding, as well as the Worster family and Worster Award (to AJM and DWH) for additional funding and support. Sources of funding did not play a role in the design of the study, analysis, interpretation of data or in the writing of the manuscript.

\section{Availability of data and materials}

The datasets generated and analyzed during the current study are available from the corresponding author upon reasonable request. Sequences are submitted in the GenBank database under accession numbers KY271962KY271964 (for B. burgdorferi (s.l.) strains from 3 nymphal I. peromysci) and KY271965 (1 adult female I. spinipalpis).

\section{Authors' contributions}

AJM conceived the study, collected ticks and abiotic data, processed samples and ran PCR assays, carried out statistical analyses and drafted the manuscript. DWH and JBB collected ticks, ran PCR assays and provided feedback on the manuscript. KEO ran PCR assays and sequenced PCR positive samples. AS aided in sequencing PCR positive samples, aided in drafting the manuscript and provided feedback on study design and implementation. CJB aided in study design and implementation, provided feedback on statistical analyses and aided in drafting the manuscript. All authors read and approved the final version of the manuscript.

\section{Competing interests}

The authors declare that they have no competing interests.

\section{Consent for publication}

Not applicable.

\section{Ethics approval and consent to participate}

Not applicable. No vertebrate or protected invertebrate animals were used in this study, nor were human participants, human data or human tissue.

\section{Author details}

${ }^{1}$ Department of Ecology, Evolution and Marine Biology, University of California, Santa Barbara, CA 93106-9620, USA. ²Department of Biology, Stanford University, 371 Serra Mall, Stanford, CA 94305, USA. ${ }^{3}$ Department of Biology, San Francisco State University, 1600 Holloway Avenue, San Francisco, CA 94132, USA.

Received: 8 September 2016 Accepted: 14 December 2016 Published online: 05 January 2017 


\section{References}

1. Weaver SC, Reisen WK. Present and future arboviral threats. Antiviral Res. 2010;85:328-45.

2. Kilpatrick AM, Randolph SE. Drivers, dynamics, and control of emerging vector-borne zoonotic diseases. Lancet. 2012;380:1946-55.

3. Gortazar C, Reperant LA, Kuiken T, La Fuente de J, Boadella M, MartínezLopez B, et al. Crossing the interspecies barrier: opening the door to zoonotic pathogens. PLoS Pathog. 2014;10(6):e1004129.

4. Barrett ADT, Higgs S. Yellow fever: a disease that has yet to be conquered. Annu Rev Entomol. 2007:52:209-29.

5. Larsen AE, MacDonald AJ, Plantinga AJ. Lyme disease risk influences human settlement in the wildland-urban interface: evidence from a longitudinal analysis of counties in the northeastern United States. Am J Trop Med Hyg. 2014;91:747-55.

6. Jackson LE, Hilborn ED, Thomas JC. Towards landscape design guidelines for reducing Lyme disease risk. Int J Epidemiol. 2006;35:315-22.

7. Lindsay SW, Birley M. Rural development and malaria control in sub-Saharan Africa. EcoHealth. 2004;1:129-37.

8. Beaujean D, Crutzen R, Kengen C, van Steenbergen J, Ruwaard D. Increase in ticks and Lyme borreliosis, yet research into its prevention on the wane. Vector Borne Zoonotic Dis. 2016;16:349-51.

9. Killilea ME, Swei A, Lane RS, Briggs CJ, Ostfeld RS. Spatial dynamics of Lyme disease: a review. EcoHealth. 2008;5:167-95.

10. Eisen RJ, Eisen L, Castro MB, Lane RS. Environmentally related variability in risk of exposure to Lyme disease spirochetes in northern California: effect of climatic conditions and habitat type. Environ Entomol. 2003;32:1010-8.

11. Eisen RJ, Eisen L, Lane RS. Predicting density of Ixodes pacificus nymphs in dense woodlands in Mendocino County, California, based on geographic information systems and remote sensing versus field-derived data. Am J Trop Med Hyg. 2006;74:632-40

12. Eisen L, Eisen RJ, Mun J, Salkeld DJ, Lane RS. Transmission cycles of Borrelia burgdorferi and $B$. bissettii in relation to habitat type in northwestern California. J Vector Ecol. 2009:34:81-91.

13. Padgett KA, Lane RS. Life cycle of Ixodes pacificus (Acari: Ixodidae): timing of developmental processes under field and laboratory conditions. J Med Entomol. 2001;38:684-93.

14. Eisen RJ, Eisen L, Girard YA, Fedorova N, Mun J, Slikas B, et al. A spatiallyexplicit model of acarological risk of exposure to Borrelia burgdorferiinfected Ixodes pacificus nymphs in northwestern California based on woodland type, temperature, and water vapor. Ticks Tick Borne Dis. 2010;1:35-43.

15. Swei A, Meentemeyer R, Briggs CJ. Influence of abiotic and environmental factors on the density and infection prevalence of Ixodes pacificus (Acari: Ixodidae) with Borrelia burgdorferi. J Med Entomol. 2011;48:20-8.

16. MacDonald AJ, Briggs CJ. Truncated seasonal activity patterns of the western blacklegged tick (Ixodes pacificus) in central and southern California. Ticks Tick Borne Dis. 2016;7:234-42.

17. Lane RS, Fedorova N, Kleinjan JE, Maxwell M. Eco-epidemiological factors contributing to the low risk of human exposure to ixodid tick-borne borreliae in southern California, USA. Ticks Tick Borne Dis. 2013;4:377-85.

18. Quantum GIS Development Team. Quantum GIS Geographic Information System. Open Source Geospatial Foundation Project. 2016. URL: http://qgis.osgeo.org.

19. Hamm KA, Diller LV, Kitchen DW. Comparison of indices to estimate abundance of dusky-footed woodrats. Wildl Soc Bull. 2002;30:64-70.

20. Bolger DT, Alberts AC, Sauvajot RM, Potenza P, McCalvin C, Tran D, et al. Response of rodents to habitat fragmentation in coastal southern California. Ecol Appl. 1997;7:552-63.

21. Tietje WD, Vreeland JK, Siepel NR, Dockter J. Relative abundance and habitat associations of vertebrates in oak woodlands in coastal-central California. USDA Forest Service Gen Tech Rep. 1997;PSW-GTR-160:391-400.

22. Daniels TJ, Falco RC, Fish D. Estimating population size and drag sampling efficiency for the blacklegged tick (Acari: Ixodidae). J Med Entomol. 2000;37:357-63.

23. Lane RS, Steinlein DB, Mun J. Human behaviors elevating exposure to Ixodes pacificus (Acari: Ixodidae) nymphs and their associated bacterial zoonotic agents in a hardwood forest. J Med Entomol. 2004;41:239-48.

24. Brown RN, Lane RS. Lyme disease in California - a novel enzootic transmission cycle of Borrelia burgdorferi. Science. 1992;256:1439-42.
25. Margos G, Lane RS, Fedorova N, Koloczek J, Piesman J, Hojgaard A, et al. Borrelia bissettiae sp. nov. and Borrelia californiensis sp. nov. prevail in diverse enzootic transmission cycles. Int J Syst Evol Microbiol. 2016;66:1447-52.

26. Padgett K, Bonilla D, Kjemtrup A, Vilcins I-M, Yoshimizu MH, Hui L, et al. Large scale spatial risk and comparative prevalence of Borrelia miyamotoi and Borrelia burgdorferi sensu lato in Ixodes pacificus. PLoS One. 2014;9:e110853.

27. Carrascal LM, Galván I, Gordo O. Partial least squares regression as an alternative to current regression methods used in ecology. Oikos. 2009;118:681-90.

28. R Core Team. R: a language and environment for statistical computing. Vienna: R Foundation for Statistical Computing; 2016. URL: https://www.Rproject.org/.

29. Sanchez G. plsdepot: Partial least squares (PLS) data analysis methods. $R$ package version 0.1.17. 2012. URL: https://CRAN.R-project.org/package= plsdepot.

30. Rudenko N, Golovchenko M, Mokracek A, Piskunova N, Ruzek D, Mallatova $\mathrm{N}$, et al. Detection of Borrelia bissettii in cardiac valve tissue of a patient with endocarditis and aortic valve stenosis in the Czech Republic. J Clin Microbiol. 2008;46:3540-3.

31. Rudenko N, Golovchenko M, Ruzek D, Piskunova N, Mallatova N, Grubhoffer L. Molecular detection of Borrelia bissettii DNA in serum samples from patients in the Czech Republic with suspected borreliosis. FEMS Microbiol Lett. 2009;292:274-81.

32. Hulínská D, Votýpka J, Vaňousová D, Hercogová J, Hulínský V, Dřevová H, et al. Identification of Anaplasma phagocytophilum and Borrelia burgdorferi sensu lato in patients with erythema migrans. Folia Microbiol. 2009;54:246-56.

33. Fedorova N, Kleinjan JE, James D, Hui LT, Peeters H, Lane RS. Remarkable diversity of tick or mammalian-associated borreliae in the metropolitan San Francisco Bay Area, California. Ticks Tick Borne Dis. 2014;5:951-61.

34. Girard YA, Fedorova N, Lane RS. Genetic diversity of Borrelia burgdorferi and detection of $B$. bissettii-like DNA in serum of north-coastal California residents. J Clin Microbiol. 2011;49:945-54.

35. Lane RS, Miller SE, Collins PW. Ticks (Acari: Argasidae and Ixodidae) from the California Channel Islands. Pan-Pac Entomol. 1982;58:96-104.

36. Ferreira MU, Castro MC. Challenges for malaria elimination in Brazil. Malar J. 2016;15:284

37. California Department of Public Health, CDPH. Epidemiologic summaries of selected general communicable diseases in California. Accessed 2016. URL: http://www.cdph.ca.gov/healthinfo/discond/Pages/LymeDisease.aspx. Accessed 15 July 2016.

38. Eisen L, Eisen RJ, Lane RS. Seasonal activity patterns of Ixodes pacificus nymphs in relation to climatic conditions. Med Vet Entomol. 2002;16:235-44.

39. Eisen RJ, Lane RS, Fritz CL, Eisen L. Spatial patterns of Lyme disease risk in California based on disease incidence data and modeling of vector-tick exposure. Am J Trop Med Hyg. 2006;75:669-76.

40. Lane RS, Mun J, Peribanez MA, Stubbs HA. Host-seeking behavior of Ixodes pacificus (Acari: Ixodidae) nymphs in relation to environmental parameters in dense-woodland and woodland-grass habitats. J Vector Ecol. 2007;32:342-57

41. Salkeld DJ, Castro MB, Bonilla D, Kjemtrup A, Kramer VL, Lane RS, et al. Seasonal activity patterns of the western blacklegged tick, Ixodes pacificus, in relation to onset of human Lyme disease in northwestern California. Ticks Tick Borne Dis. 2014;5:790-6.

42. Arsnoe IM, Hickling GJ, Ginsberg HS, McElreath R, Tsao Jl. Different populations of blacklegged tick nymphs exhibit differences in questing behavior that have implications for human Lyme disease risk. PLoS One. 2015;10:e0127450.

43. Ogden NH, Bigras-Poulin M, O'Callaghan CJ, Barker IK, Lindsay LR, Maarouf A, et al. A dynamic population model to investigate effects of climate on geographic range and seasonality of the tick Ixodes scapularis. Int J Parasitol. 2005:35:375-89.

44. Ogden NH, Maarouf A, Barker IK, Bigras-Poulin M, Lindsay LR, Morshed MG, et al. Climate change and the potential for range expansion of the Lyme disease vector Ixodes scapularis in Canada. Int J Parasitol. 2006;36:63-70.

45. Ogden NH, Bigras-Poulin M, Hanincová K, Maarouf A, O'Callaghan CJ Kurtenbach K. Projected effects of climate change on tick phenology and fitness of pathogens transmitted by the North American tick Ixodes scapularis. J Theor Biol. 2008;254:621-32.

46. Ogden NH, Radojević M, Wu X, Duvvuri VR, Leighton PA, Wu J. Estimated effects of projected climate change on the basic reproductive number of the Lyme disease vector Ixodes scapularis. Environ Health Perspect. 2014;122:631-8. 
47. Levi T, Keesing F, Oggenfuss K, Ostfeld RS. Accelerated phenology of blacklegged ticks under climate warming. Philos Trans R Soc Lond B Biol Sci. 2015;370:20130556.

48. Hayhoe K, Cayan D, Field CB, Frumhoff PC, Maurer EP, Miller NL, et al. Emissions pathways, climate change, and impacts on California. Proc Natl Acad Sci U S A. 2004;101:12422-7.

49. Cayan DR, Maurer EP, Dettinger MD, Tyree M, Hayhoe K. Climate change scenarios for the California region. Clim Chang. 2008;87:21-42.

Submit your next manuscript to BioMed Central and we will help you at every step:

- We accept pre-submission inquiries

- Our selector tool helps you to find the most relevant journal

- We provide round the clock customer support

- Convenient online submission

- Thorough peer review

- Inclusion in PubMed and all major indexing services

- Maximum visibility for your research

Submit your manuscript at www.biomedcentral.com/submit 